Paidéia, 2006, 16(34), 181-192

\title{
ESTUDO COMPARATIVO SOBRE PERCEPÇÕES DE CARACTERÍSTICAS SÓCIO-PRO- FISSIONAIS DE TRABALHADORES EM GERAL E DE IMIGRANTES NEGROS DOS PALOP AFRICANOS EM PORTUGAL ${ }^{1}$
}

\author{
Nelson Lima Santos ${ }^{2}$ \\ Universidade Fernando Pessoa - Porto \\ Luísa Faria \\ FPCE -Universidade do Porto
}

\begin{abstract}
Resumo: Neste artigo apresenta-se um estudo comparativo sobre as percepções de características sócio-profissionais (positivas e negativas) de trabalhadores em geral e trabalhadores negros africanos, imigrantes de países de língua oficial portuguesa (PALOP), vistas por estes e por portugueses brancos que trabalham com imigrantes negros, numa amostra de 200 residentes de Lisboa, 100 de etnia branca e 100 de negra, de ambos os sexos, desempenhando funções de executante. Para a coleta de dados foi construído um questionário específico, administrado individual e colectivamente no local de trabalho dos participantes. Os resultados obtidos mostram que urge transformar e melhorar as condições sócio-laborais destes imigrantes - tornando mais céleres e transparentes suas condições de legalização e permanência em Portugal, responsabilizando empregadores em particular e, cidadãos em geral, pela denúncia de situações de exploração e ilegalidade - pois a integração social deverá ser sinônimo de convivência e respeito e não de assimilação.
\end{abstract}

Palavras-chave: imigrantes; PALOP; percepções; características sócio-profissionais; etnia.

\section{COMPARATIVE STUDY ABOUT PERCEPTIONS OF SOCIO-PROFESSIONAL CHARACTERISTICS FROM ORDINARY WORKERS AND AFRICAN PALOP IMMIGRANTS IN PORTUGAL}

\begin{abstract}
This paper presents a comparative study about the perceptions of socio-professional characteristics (positive and negative) from ordinary workers and African workers from Portuguese expression countries (PALOP) perceived by those immigrants and also by Caucasian Portugueses working with them, a sample of almost 200 workers from Lisbon and surroundings, 100 Caucasian and 100 Afro-Descendents, from both genders. A specific questionnaire was built (based on previous interviews), collectively and individually administered in the subject's work place. The results allow one to conclude the need to transform and improve the immigrants' socio-labor conditions, by making their conditions of legalization and permanence in Portugal quicker and transparent, and also by promoting the responsibility of employers in particular and of citizens in general for denouncing the situations of exploration and illegality, due to their social integration should be a signal of conviviality and of respect instead of assimilation.
\end{abstract}

Key words: immigrants; PALOP; perceptions; socio-professional characteristics; ethnic group.

\section{Introdução}

A história secular de Portugal tem-se construído em torno de fenômenos de emigração, para vários continentes e países. Contudo, a revolução de 25 de

\footnotetext{
${ }^{1}$ Recebido em 04/08/06 e aceito para publicação em 05/10/06.

${ }^{2}$ Endereço para correspondência: Nelson Lima Santos, Praça 9 de Abril, 349, 4249-004, Porto-Portugal, E-mail: limasant@ufp.pt. ${ }^{3}$ Endereço para correspondência: Luisa Faria, Rua Dr. Manuel Pereira da Silva, 4200-392, Porto-Portugal , E-mail: 1faria@fpce.up.pt.
}

Abril de 1974 e a posterior integração na Comunidade Européia constituem dois marcos ou momentos em que esta história nacional começa a mudar, de tal modo que, segundo os dados de 2001/2002 do Serviço de Estrangeiros e Fronteiras, tem-se atualmente mais de trezentos e cinquenta mil imigrantes legais (residentes e com autorização de permanência).

Ora, nos fenômenos migratórios humanos, segundo as palavras de Ferreira de Castro (1977) 
"Os homens transitam do Norte para o Sul, de Leste para Oeste, de país para país, em busca de pão e de um futuro melhor. ... Mas, em todo o Mundo, ou em quase todo o Mundo, vão encontrar drama semelhante, porque semelhantes são as leis que regem o aglomerado humano. Não esmorecem, apesar disso. Continuam a transitar de olhos postos na luz que a sua imaginação acendeu ..." (p.5-6). E esta breve citação do emigrante-escritor mantém na perspectiva toda a pertinência, pois o fenômeno da imigração mais do que se constituir como um dos temas da atualidade quotidiana e mediática, é um dos problemas com consequências políticas, culturais, econômicas e psicossociais mais profundas, no continente Europeu.

Assim, Portugal também não está alheio a esta problemática, debatendo-se com o fenômeno de imigração, oriunda não apenas das suas ex-colônias, mas também proveniente do leste Europeu, particularmente dos países do ex-bloco socialista. No entanto, ele é ainda um dos países europeus com menor quantidade de imigrantes, cuja expressão associativa é também recente e incipiente (Silva \& Silva, 2002); na verdade, (Pires, 2002), é só a partir do início dos anos 80 que Portugal passa a ser um país de imigração. E, com o aumento dos fluxos migratórios, enfrenta dois problemas: um de cunho quantitativo - a integração de um grande número de pessoas em determinadas regiões do país -, outro qualitativo -a inclusão social de pessoas, étnica, cultural e religiosamente diferentes.

Esta problemática pode gerar tensões e conflitos, nomeadamente porque largos estratos da população portuguesa ainda se debatem com fortes problemas econômicos, que os colocam também na situação de emigrantes ou de desfavorecidos sócio-econômica e culturalmente, podendo perceber os imigrantes como potenciais "usurpadores" de direitos e de privilégios até aí reservados às populações autótones (Silva \& Silva, 2002); neste quadro, parece urgente efetuar estudos sobre as percepções que os imigrantes e os portugueses têm uns dos outros, nomeadamente do ponto de vista sócio-profissional, pois este é um contexto que tende a ser propício à emergência de dificuldades de convivência, sobretudo porque o trabalho é um bem cada vez mais escasso no atual contexto sócio-econômico.
Assim, este trabalho visa apresentar o desenvolvimento e os resultados de um estudo comparativo sobre as percepções das características sócio-profissionais de trabalhadores portugueses e de negros africanos, imigrantes dos países de língua oficial portuguesa (PALOP), características estas percepcionadas pelos imigrantes e por portugueses brancos que trabalham com eles.

O objetivo do estudo é pois contribuir para clarificar as percepções sociais que estes dois grupos de trabalhadores têm um do outro, no sentido de promover o desenvolvimento de mecanismos de facilitação da inclusão profissional, como instrumento impulsionador da inclusão sócio-econômica e cultural dos imigrantes na sociedade que os acolhe, nomeadamente dos africanos oriundos dos PALOP, que partilham com os portugueses um passado histórico, político, cultural e sócio-econômico comum de vários séculos.

\section{Fluxos migratórios de africanos dos PALOP para Portugal}

Após o 25 de Abril de 1974, verifica-se um aumento de fluxos migratórios de africanos para Portugal, com particular incidência das ex-colônias, apresentando, tendencialmente, perfis sociológicos muito diversos daqueles que caracterizavam os pequenos fluxos ocorridos na década anterior; enquanto os primeiros eram movidos essencialmente por objetivos educacionais e econômicos, os segundos deslocamse num contexto de mudanças políticas radicais, nomeadamente de guerra civil entre diferentes movimentos, partidos ou facções político-militares.

Mais ainda, o fluxo migratório proveniente dos países africanos de expressão portuguesa tem se acentuado nas últimas décadas porque, segundo Carita e Rosendo (1993), nos anos setenta, a “... uma grave crise de mão-de-obra em Portugal, causada pela emigração portuguesa e pela participação de milhares de jovens na Guerra Colonial ..." seguiu-se, após a independência destes países, “... um surto acrescido ... de imigrantes clandestinos, de mulheres, irmãos e filhos" (p.142)..

Estes fatos levam a explorar, mesmo que brevemente, alguns aspectos dos contextos econô- 
micos, políticos e históricos dos países de origem destes fluxos migratórios africanos para Portugal. Assim, verifica-se que na década de oitenta é possível referenciar "a cristalização de um novo padrão migratório marcado pela consolidação do movimento social, com origem em Cabo Verde, e o seu progressivo alargamento aos restantes PALOP, bem como pela persistência de migrações forçadas de menor amplitude envolvendo, sobretudo, refugiados vindos de Angola e de Moçambique (Saint-Maurice, 1994, p. 126). De fato, na "sequência do movimento de Abril de 74 e da descolonização em África, há que frisar o regresso de milhares de portugueses residentes nas ex-colônias, e de imigrantes africanos que se fixam em Portugal" (Machado, 1997, p. 21).

Na verdade, os PALOP africanos apresentam sinais e evidências que os situam no nível de uma economia de subsistência, centrada na produção agrícola, com fraca produtividade e subemprego ou desemprego persistentes, que têm conduzido a um aumento da dependência do trabalho assalariado e, sobretudo, ao êxodo rural. Este quadro caracteriza-se pela falta de capacidade de absorção da mão-de-obra pelo mercado de trabalho, pelo ritmo lento da industrialização, pobreza dos meios de produção, forte desemprego urbano e saída de mão-de-obra para o estrangeiro. O processo de descolonização, as guerras e as políticas pós-coloniais, a par de características geográficas, climatéricas e a pobreza em recursos do meio rural, ainda fazem aumentar o número de indivíduos e de famílias que "fogem a contextos de mudança e instabilidade política e, particularmente, a situações de guerra, podendo por isso ser considerado como migração de refugiados" (Machado, 1997, p. 21).

\section{Caracterização dos imigrantes negros dos PALOP africanos}

A situação dos africanos dos PALOP em Portugal pode ou não ser de imigração, contribuindo para esta falta de clarificação "os processos de descolonização que levaram à formação de 'retornos involuntários' de nacionais portugueses de ascendência africana e seus descendentes." (Pires, 2002, p. 250 ), pelo que parece oportuno caracterizar estes imigrantes.

\section{Localização geográfica}

É nas zonas periféricas da capital e de alguns centros urbanos a sul do país (Lisboa, Setúbal e Faro) que se encontra a maior parte da população africana dos PALOP: de acordo com Machado (1999), é em Lisboa, no Vale do Tejo, que os africanos dos PALOP permanecem em maior número. Com baixos recursos econômicos, estes imigrantes "ocupam espaços urbanos e periféricos, geralmente degradados e marginalizados, que favorecem a 'ghettização' e o isolamento" (SOS Racismo, 1992, p. 46).

Esta "geografia de marginalidade" tem um impacto negativo na qualidade de vida, na segurança e saúde pública dos seus habitantes, promovendo comportamentos desadaptados e anti-sociais em crianças, adolescentes e adultos (Simões, 2002), o papel do ambiente físico e da localização geográfica condiciona aspectos particulares da vida sócio-econômica destas populações, afetando as redes de relações sociais e a percepção individual e coletiva dos membros destes grupos, que se assumem como de uma "cidade oculta", plena de degradação social, econômica e individual, constituída à margem da "cidade pública" (Simões, 2002).

\section{Enquadramento familiar}

A imigração de africanos dos PALOP não deixa de ser de carácter familiar, ou melhor, uma imigração tipificada pela "reunião familiar numa migração por etapas" que, "para além de traduzir uma intenção de permanência longa, possibilita o estabelecimento de redes de suporte reduzindo os custos da integração, tanto no plano meramente instrumental, como nos domínios afetivo e simbólico" (Carlos et al., 1991, p. 52).

Os mesmos autores referem que, estes imigrantes dos PALOP, residentes em Portugal em 1981, cerca de " $64 \%$ estavam integrados em núcleos familiares, compostos pelos cônjuges e filhos solteiros e, cerca de $8 \%$, partilhavam o alojamento com três ou mais núcleos familiares e apenas $9 \%$ tinha imigrado sem filhos" (op. cit., p. 52), saliente-se que o perfil sócio-cultural das populações dos PALOP, nos domínios da estrutura familiar e das práticas de sociabilidade, lhes permite coabitar no mesmo alojamento, sobretudo num primeiro momento, com familiares mais afastados ou amigos, de tal modo que é entre estes "grupos de nacionalidades que surgem as mais altas percentagens de residentes em alojamentos com três e mais núcleos familiares" (Carlos et al., 1991, p. 52). 
Em suma, parece que este panorama de falta de espaço pessoal e privado, em áreas habitacionais diminutas e degradadas, condiciona a construção da identidade do eu, pois a habitação se constitui também em elemento estruturante do desenvolvimento sócio-emocional dos indivíduos.

\section{Condições habitacionais}

Numa situação de grande desfavorecimento, os imigrantes africanos dos PALOP habitam em "alojamentos móveis ou em barracos" (Carlos et al., 1991, p. 54) e, apesar das diferenças sócio-culturais que eles têm, assiste-se a "uma tendência de concentração residencial das diferentes comunidades" (p. 54), de tal modo que no mesmo bairro se encontram caboverdianos, angolanos, moçambicanos, são- tomenses e guinienses. Ora, uma das principais causas desta "unidade" consiste no relacionamento e nos "laços de solidariedade" que estes imigrantes estabelecem entre si. Além disso, contribuem com incentivos à vinda de "patrícios" e conterrâneos, desenvolvendo ainda mecanismos de entreajuda para a construção ou melhoramento das habitações. A habitação constitui, então, "um dos indicadores mais importantes no aferimento das condições de vida destes imigrantes e, consequentemente, na determinação do processo de integração social" (p. 54).

Salienta-se, ainda, que a segregação de que são alvo provoca problemas inerentes a este modo de viver e de existir, que são comuns à maioria das populações nas mesmas condições de habitação, independentemente da nacionalidade, cor ou religião: na verdade, a "ausência de infra-estrutura, de saneamento básico, realça o fato de que, para a sociedade envolvente, estes núcleos habitacionais estão quase sempre conotados como centros de marginalidade e delinqüência, o que leva ao desenvolvimento de sentimentos de rejeição, defesa e violência" (SOS Racismo, 1992, p. 47).

Ou seja, pode-se afirmar que as condições degradantes das habitações destas populações, quase sempre temporárias, mas também definitivas, condicionam as relações dos indivíduos e também suas percepções e desenvolvimento global, afetando ainda as percepções que os outros têm acerca deles.

Assim, as condições de habitação, com falta de infra-estrutura como água canalizada, eletricidade e saneamento básico, mais a área habitacional constituída por espaços mal aproveitados, degradados do ponto de vista ambiental, voltados à marginalidade e dependência, favorecem a emergência de comportamentos desadaptados e anti-sociais (Simões, 2002).

\section{Nível de escolaridade e sócio-profissional}

O nível de escolaridade constitui um recurso básico no processo de integração dos imigrantes africanos dos PALOP na sociedade de acolhimento, condicionando não só o tipo de inserção no mercado de trabalho, mas também a interação com a população receptora, tanto no plano instrumental como no comunicacional: ora, entre estes imigrantes, a escolaridade permanece largamente insuficiente, apesar de no período de pós-independência dos PALOP africanos ter havido um esforço considerável de escolarização, o que permitiu a muitos jovens, sobretudo nos centros urbanos, completar o ensino secundário e, até, alguns acederem ao ensino superior.

Os jovens imigrantes, interessados em continuar seu trajeto escolar em Portugal, se confrontam com canais estreitos, pois a oferta de ensino superior no país é recente, limitada e cobre apenas um leque restrito de áreas, ao que se junta o fato de as bolsas de estudo para estrangeiros serem sempre em número inferior ao dos candidatos. A obtenção ou não de tais bolsas representa, para muitos, uma verdadeira "encruzilhada para vidas divergentes" (Machado, 1998, p.13); os que as conseguem podem mais tarde regressar ou, até mesmo, permanecer no país onde estudaram como técnicos, enquanto que os não "contemplados são obrigados a dar por terminado o trajeto escolar, o que, na maioria dos casos, não corresponde aos projetos pessoais" (p.13).

Salienta-se que o insucesso escolar e as representações negativas da escola, com desistência precoce dado o fracasso, desresponsabilização pelos resultados, sentimentos de desânimo e abandono aprendido (Faria, 1998), são alguns dos aspectos que caracterizam a vivência da escolaridade por parte de muitas crianças e adolescentes negros dos PALOP: portanto, os padrões motivacionais de desistência condicionam negativamente o investimento na escolaridade, como meio crucial de transformação dos percursos individuais e sociais. 
Todavia, realça-se o contraste entre os perfis de uma "migração atomizada e rejuvenescida, por um lado, e uma familiar e com grande peso de população adulta, por outro, contraste este que se caracteriza na dicotomia definida a partir de indicadores relativos à condição perante o trabalho e nível de qualificação" (Saint-Maurice, 1994, p.131), com efeito, verifica-se que ao primeiro perfil corresponde um grande número de estudantes, com níveis de qualificação intermediários, e ao segundo uma elevada proporção de população ativa, com baixos níveis de qualificação.

No que diz respeito ao trabalho, que é um dos indicadores mais importantes de integração, uma vez que o tipo de inserção no mercado condiciona o acesso a condições de habitação e de vida, constata-se que "a generalidade dos ativos está presente nos setores com piores condições, mais baixas remunerações e com menores possibilidades de promoção" (SOS Racismo, 1992, p. 52).

Muitos dos trabalhadores estão ligados ao setor da construção civil e obras públicas (para o sexo masculino), aos serviços pessoais ou domésticos (para o sexo feminino), aos restaurantes ou hotéis e ao pequeno comércio, setores estes que também são os que mais recorrem à mão-de-obra clandestina, como forma de reduzir custos de produção: e, concomitantemente, a outra face desta situação é que estes também são trabalhadores sem os direitos e regalias sociais e laborais que os deviam proteger.

Portanto, embora a maioria dos PALOP africanos apresentem uma "falta de educação formal e de formação profissional", parece que a posição que ocupam no mercado de trabalho resulta, sobretudo, de fatores de ordem social, designadamente do sistema de emprego, caracterizado por uma "crescente flexibilização das leis laborais e proliferação de formas atípicas de emprego" (p. 52), perante situações destas, a maioria dos trabalhadores africanos oriundos dos PALOP sujeitam-se, sem alternativa, a uma permanente insegurança e precariedade nas condições de trabalho, o que não favorece de modo algum os seus sentimentos de pertença e de integração na sociedade portuguesa.

Em suma, muitos imigrantes africanos dos PALOP viveram "o confronto entre o mundo tradicional e o urbano, entre os valores míticos da cultura cam- ponesa e a fria racionalidade dos acontecimentos bélicos, caracterizados pela tecnologia sofisticada da guer$\mathrm{ra}$, o constante choque entre a harmonia gregária coletiva no seu habitat tradicional e a desordem caótica que a miséria e os desequilíbrios sociais provocaram nas margens urbanas e suburbanas" (Leite, 1998, p. 41), sendo, contudo, na transição para um país, mais industrializado do que o de origem, num novo espaço e continente, que procuram a reconstrução das identidades, ganhando novas referências e renegociando outras (Saint-Maurice, 1994).

No entanto, conforme se pode observar a partir da análise de indicadores sobre a população imigrante negra dos PALOP africanos, nomeadamente as suas condições habitacionais, escolares e sócioprofissionais, constata-se que a sociedade portuguesa lhes dificulta as condições que poderiam evitar a formação de estereótipos e preconceitos que impedem interacções mais positivas entre portugueses e imigrantes africanos dos PALOP, que se constituem assim como um grupo minoritário e fragilizado do ponto de vista sócio-econômico e cultural.

O termo "minoria", segundo Fernandes (1995), significa que "existe um subconjunto menor em número do que outros subconjuntos ou conjuntos. Em que a maioria prevalece em número ou em poder"'(p.24). Por sua vez, Moscovici (1979) considera que o termo minoria reflete o impacto do indivíduo ou do sub-grupo sobre a opinião do grupo, que é menor.

Então, as minorias podem ser percebidas como espaços ideológicos, realidades alienígenas, que se constituem como corpo estranho, ou, em sentido positivo, como grupos portadores de projetos futuros, podendo, em termos qualitativos, ser assumidos como maiorias, se transformadas em grupos dominantes.

Assim, pode-se considerar que as minorias constituem agrupamentos que não participam plenamente da vida social, cultural e política de um país, conforme já observado para os imigrantes africanos dos PALOP em Portugal.

\section{Conceito de Etnia}

Noutra perspectiva, do ponto de vista étnico, o termo minoria tende a ser substituído pela expressão "grupo étnico": deste modo, sabendo-se que a etnia pode ser definida como "um agrupamento de famílias numa área geográfica, cuja unidade assenta numa es- 
trutura familiar, econômica e social comum e numa cultura comum" (Lello \& Lello, 1988, p. 933), vê-se, então, que "as etnias constituem-se de minorias que apresentam um certo grau de distanciamento em relação aos padrões normais de conduta" (Fernandes, 1995, p. 25). De fato, o grupo étnico é marcado por traços característicos que o diferenciam do resto da população, principalmente quando possui uma cultura própria e uma religião específica, sendo também identificado por traços fisionômicos particulares, que fazem destes grupos "um mundo à parte, com o seu sistema de relações sociais e a sua vivência cultural.” (p. 25).

Segundo Monteiro (2002), o conceito de etnia apresenta uma grande variedade de acepções para além do seu sentido original (oriundo do grego ethnos, que exprime a existência de povos ou grupos humanos diferentes); na verdade, o seu sentido mais coerente e uniforme é visto quando se aplica a grupos dominados, através do discurso dos dominantes acerca de quem se quer distinguir e diferenciar. Assim, geralmente, a utilização da designação etnia é para grupos não brancos, imigrados, de baixa condição social e com diferenças linguísticas e religiosas em relação ao grupo dominante.

Nesta perspectiva, concorda-se com Monteiro (2002, p. 273) quando afirma, tal como outros investigadores sociais, “...que o conceito de etnia é uma construção social semântica proposta pelos grupos dominantes ocidentais (cientistas e políticos), que foi reificada, institucionalizada e consensualmente adotada pelo senso comum, correspondendo a um recorte de certas variações físicas, ideológicas ou comportamentais das comunidades humanas, socialmente dotadas de significado", contudo, no contexto deste estudo, o termo etnia será utilizado de forma indiferenciada, sendo aplicado a todo e qualquer grupo.

\section{Identidade étnica}

O conceito de identidade étnica desenvolve-se nos países de acolhimento através de processos de interação social, a partir de percepções de grupo que os nacionais têm acerca dos que consideram diferentes, pobres e culturalmente atrasados, o que os leva a designá-los como etnias, ao contrário de outros grupos que são designados apenas como estrangeiros (Bastos \& Bastos, 1999), talvez seja por isso que nunca se fala dos ingleses estabelecidos em Portugal (em nú- mero significativo) como etnia inglesa, embora se fale de etnia cigana ou cabo-verdiana (Monteiro, 2002).

Mas, a identidade étnica, ou o sentimento de pertença a um grupo, inclui não apenas o sentimento de compromisso e de partilha de valores e atitudes, mas também a avaliação do significado emocional da pertença a esse grupo para o indivíduo - auto-estima, orgulho, bem-estar, percepção de pertença ou, até, desejo de pertencer a outro grupo (Monteiro, 2002).

O desenvolvimento da identidade étnica depende de fatores familiares, como os processos de socialização no seio da família, bem como de ambientais ampliados, como o grupo étnico a que se pertence e a sociedade que acolhe. No caso particular desta, ela pode evidenciar diversas formas de discriminação, nomeadamente econômica, social e racial, e, por vezes, mesmo a inacessibilidade aos direitos sociais, políticos para os grupos minoritários, gerando conflitos e sentimentos de culpabilidade social (Moscovici, 1979; Xavier de França \& Monteiro, 2004). Em suma, "os grupos étnicos tanto servem para a tomada de uma consciência de identidade por parte do grupo, como para serem hostilizados pelos grupos que detêm o poder no espaço social onde agem" (Dicionário de Sociologia, 2002, p. 183).

\section{Estudo comparativo das percepções de carac- terísticas sócio-profissionais}

Nesta linha se apresenta um estudo, com caráter exploratório, sobre as percepções de características sócio-profissionais diferenciais dos trabalhadores negros dos PALOP em Portugal, comparando-as com as dos trabalhadores em geral, questionando quer os deste grupo, quer do de brancos portugueses. Pretende-se, deste modo, identificar as principais diferenças percebidas por ambos os grupos o minoritário (trabalhadores africanos negros dos PALOP) e o majoritário (trabalhadores brancos portugueses) - na percepção de características positivas e negativas do ponto de vista sócio-profissional.

Elegeu-se a área sócio-profissional porque esta se apresenta como uma das que possui maior visibilidade social, permitindo a observação direta dos comportamentos e desempenho dos indivíduos e também porque o trabalho marca indelevelmente a identidade de cada indivíduo, sendo fonte de bem-estar, de reconhecimento e de transformação social. 


\section{Objetivos}

O presente estudo foi efetuado na área metropolitana de Lisboa, por ser aí que existe maior concentração de trabalhadores imigrantes e, particularmente, de etnia negra, oriundos dos PALOP africanos, aí concentrados, desde algumas décadas.

O objetivo fundamental foi explorar as percepções de características sócio-profissionais diferenciais (positivas e negativas) dos trabalhadores em geral e dos negros imigrantes dos PALOP africanos, questionando este grupo acerca de características, positivas e negativas, de trabalhadores e dos negros imigrantes dos PALOP, e um grupo de portugueses brancos que trabalham com imigrantes negros acerca das mesmas características.

\section{Método}

Amostra: Participaram neste estudo 200 trabalhadores de vários setores de atividade, nomeadamente da construção civil, limpezas e pequeno comércio da região de Lisboa, distribuindo-se por quatro grupos distintos em função da etnia e do sexo: 50 mulheres e 50 homens de etnia branca e 50 mulheres e 50 homens de etnia negra.

Tabela 1 - Caracterização sócio-demográfica da amostra

\begin{tabular}{|c|c|c|c|c|c|c|}
\hline & \multicolumn{5}{|c|}{ Etria } \\
\hline & \multicolumn{3}{|c|}{ Branca } & \multicolumn{3}{c|}{ Negra } \\
\hline Sexo & F & M & Total & F & M & Total \\
\hline Idade & & & & & & \\
\hline Até 35 anos & 45 & 33 & 78 & 40 & 35 & 75 \\
\hline 36 a 50 anos & 2 & 10 & 12 & 9 & 11 & 20 \\
\hline$\geq 51$ anos & 3 & 7 & 10 & 1 & 4 & 5 \\
\hline Total & 50 & 50 & 100 & 50 & 50 & 100 \\
\hline Nivel de Escolaridade & & & & & & \\
\hline Até ao $6^{\circ}$ ano & 2 & 4 & 6 & 3 & 4 & 7 \\
\hline $7^{\circ}$ ao $9^{\circ}$ ano & 1 & 7 & 8 & 10 & 6 & 16 \\
\hline $10^{\circ}$ ao $12^{\circ}$ ano & 24 & 15 & 39 & 20 & 15 & 35 \\
\hline Ensino Superior $^{2}$ & 23 & 24 & 47 & 17 & 25 & 42 \\
\hline Total & 50 & 50 & 100 & 50 & 50 & 100 \\
\hline Tipo de Funções & & & & & & \\
\hline Executante & 40 & 25 & 65 & 41 & 28 & 69 \\
\hline Técnico/Chefia Directa & 8 & 17 & 25 & 4 & 14 & 18 \\
\hline $\begin{array}{c}\text { Quadro Superiorl } \\
\text { Gestor/Empresário }\end{array}$ & 2 & 8 & 10 & 5 & 8 & 13 \\
\hline Total & 50 & 50 & 100 & 50 & 50 & 100 \\
\hline
\end{tabular}

O que se pode constatar na Tabela 1, a maioria dos negros têm idade até 35 anos (75\%); a escolaridade varia entre $10^{\circ}$ e o $12^{\circ}$ anos $(35 \%)$ e ensino superior $(42 \%)$; a maioria desempenha funções de executante $(69 \%)$. Os brancos, na sua maioria, também têm idade até 35 anos (78\%), sua escolaridade varia de $10^{\circ}$ e o $12^{\circ}$ ano (39\%) e o ensino superior (47\%); a maioria desempenha funções de executante $(65 \%)$. Assim, são duas sub-amostras, em função da etnia (branca x negra), semelhantes do ponto de vista etário, sócio-cultural e sócio-profissional, com predominância de indivíduos jovens, com escolaridade média e superior e funções de executante, seguidas das de técnico/chefia direta. A semelhança entre as sub-amostras, do ponto de vista sócio-demográfico (sexo, idade, escolaridade e estatuto sócio-profissional), permite uma comparação mais rigorosa das percepções/opiniões baseada em critérios de etnia, pois esta é a única característica/variável que distingue os participantes.

\section{Procedimento}

O instrumento utilizado foi concebido especificamente para este estudo: trata-se de um questionário construído a partir da realização prévia de doze entrevistas, concretizadas com dois grupos distintos: um de seis indivíduos de etnia branca (portugueses), que trabalhavam com etnia negra, imigrantes dos PALOP africanos, e outro de seis indivíduos de etnia negra, imigrantes dos PALOP africanos, que lidavam com portugueses de etnia branca.

O questionário foi elaborado a partir da análise de conteúdo das entrevistas, sendo constituído por nove questões, das quais cinco fechadas, compreendendo aspectos de caracterização sócio-demográfica (sexo, etnia, idade, nível de escolaridade, tipo de função desempenhada), e quatro abertas, com o objetivo de conhecer a opinião sincera (percepções) dos inquiridos acerca das características sócio-profissionais (positivas e negativas) dos trabalhadores em geral e dos imigrantes negros dos PALOP africanos. Assinale-se que, neste tipo de estudo, a utilização de questões abertas é útil porque também permite realizar uma análise exploratória das características que surgem com maior frequência, podendo facilitar a construção, no futuro, de formas de avaliação mais apuradas (Lima Santos, 1998). 
O questionário foi administrado nos locais de trabalho dos participantes, após autorização dos responsáveis, de forma individual ou coletiva, de acordo com as circunstâncias. Os participantes foram informados dos objetivos do estudo, da confiden-cialidade e anonimato das respostas, bem como do caráter voluntário da sua participação. Após sua anuência, as instruções foram transmitidas oralmente, não tendo surgido dúvidas no preenchimento do questionário (que durou, em média, 10 minutos)

\section{Resultados e Discussão}

As respostas às questões abertas foram codificadas e submetidas a análises de conteúdo por categorias, em que a unidade de contexto foi o caráter "positivo" ou "negativo" das "características sócioprofissionais dos trabalhadores em geral" e dos "negros imigrantes dos PALOP africanos".

O processo de contagem utilizado foi a frequência, isto é, o número de vezes que surge a unidade de registro (a palavra), sendo as frequências apresentadas de acordo com a etnia dos inquiridos (branca x negra). Seguem-se as unidades de registro que possuem frequências iguais ou superiores a 5 respostas (ou seja, referidas por pelo menos $5 \%$ dos participantes em função da etnia), considerando-se uma resposta (a primeira) por pergunta. As unidades de registro com frequência inferior a 5 foram agrupadas com a designação "outras".

Nas Tabelas 2 a 5 são apresentados os resultados das análises de conteúdo.

Tabela 2- Percepções de características sócio-profissionais positivas dos trabalhadores-etnia

\begin{tabular}{|c|c|c|c|c|c|}
\hline \multirow{2}{*}{ Caracteristicas Positivas } & \multicolumn{2}{|c|}{ Etria Branca } & \multirow{2}{*}{ Caracteristicas Positivas } & \multicolumn{2}{|c|}{ Etnia Negra } \\
\hline & $n$ & $\%$ & & $n$ & $\%$ \\
\hline Responsável & 26 & 26 & Honesto & 28 & 28 \\
\hline Honesto & 16 & 16 & Responsável & 13 & 13 \\
\hline Competente & 13 & 13 & Profissional & 12 & 12 \\
\hline Empenhado & 11 & 11 & Pontual & 10 & 10 \\
\hline Cumpridor & 6 & 6 & Dedicado & 8 & 8 \\
\hline Dedicado & 6 & 6 & Eficiente & 7 & 7 \\
\hline Eficiente & 6 & 6 & Trabalhador & 7 & 7 \\
\hline Profissional & 6 & 6 & Competente & 6 & 6 \\
\hline $\begin{array}{l}\text { "Outras" (Polivalente, } \\
\text { Persistente, Pontual, } \\
\text { Leal e Tolerante) }\end{array}$ & 10 & 10 & $\begin{array}{c}\text { "Outras" (Disciplinado, } \\
\text { Polivalente, Qualificado } \\
\text { e Empenhado) }\end{array}$ & 9 & 9 \\
\hline Total & 100 & 100 & Total & 100 & 100 \\
\hline
\end{tabular}

Assim, na Tabela 2 pode-se observar as percepções de características sócio-profissionais positivas dos trabalhadores em geral, mencionadas pelos participantes de ambas as etnias (branca x negra), que se apresentam semelhantes, pois as de "responsável" e "honesto" aparecem nos dois primeiros lugares para ambos os grupos, invertendo-se apenas sua posição em função da etnia, apresentando-se a característica "responsável" como a mais importante para os brancos e a de "honesto" para os negros. Assinale-se que as características "dedicado" e "eficiente" surgem, em ambos os grupos, com frequências sensivelmente idênticas, enquanto que as de "competente" e "profissional" são, respectivamente, as terceiras mais valorizadas pelos brancos e negros. Dentro das com maior frequência, a de "cumpridor" é citada apenas pelos brancos e a de "trabalhador" só pelos negros, enquanto que a de "empenhado" é mais valorizada pela etnia branca e a de "pontual" pela negra. De modo geral, pode-se concluir que não se observam diferenças nas percepções de características positivas dos trabalhadores mencionadas pelas duas etnias, se se omitir a valorização diferente do empenho (pela etnia branca) e da pontualidade (pela negra).

Tabela 3-Percepções de características sócio-profissionais negativas dos trabalhadores-etnia

\begin{tabular}{|c|c|c|c|c|c|}
\hline \multirow{2}{*}{ Caracteristicas Negativas } & \multicolumn{2}{|c|}{ Etria Branca } & \multirow{2}{*}{ Caracteristicas Negativas } & \multicolumn{2}{|c|}{ Etria Negra } \\
\cline { 2 - 6 } & $n$ & $\%$ & & $n$ & $\%$ \\
\hline Preguiçoso & 24 & 24 & Desonesto & 23 & 23 \\
\hline Irresponsável & 18 & 18 & Irresponsíavel & 18 & 18 \\
\hline Desleixado & 15 & 15 & Preguiçoso & 15 & 15 \\
\hline Desonesto & 12 & 12 & Desqualificado & 14 & 14 \\
\hline $\begin{array}{c}\text { Desmotivado } \\
\text { Incompetente }\end{array}$ & 10 & 10 & Pouco Pontual & 12 & 12 \\
\hline $\begin{array}{c}\text { "Outras" (Excesso de } \\
\text { Ambição, Pouco Pontual, } \\
\text { Pouco Empenhado e } \\
\text { Pouco Profissional) }\end{array}$ & 11 & 11 & Excesso de Ambição & 10 & 10 \\
\hline Total & 100 & 100 & Desleixado, Conflituoso e & 8 & 8 \\
\hline
\end{tabular}

De acordo com os dados da Tabela 3, as percepções de características sócio-profissionais negativas dos trabalhadores em geral, ser "preguiçoso" apresenta-se como a mais importante para a etnia branca, seguida da "irresponsável", enquanto que para 
a negra "desonesto" apresenta-se em primeiro lugar, logo seguida da "irresponsável", tal como aconteceu para a etnia branca. Assim, as características "preguiçoso", "irresponsável" e "desonesto" surgem citadas por ambas as etnias de forma significativa. Já "desleixado", "pouco pontual" e "excesso de ambição" aparecem no dois grupos, mas com frequências muito diferentes, sendo a primeira mais valorizada pelos brancos e as duas seguintes pelos negros. Dentre as com maior frequência, "desmotivado" e "incompetente" só são citadas pelos brancos e "desqualificado" pelos negros. Em suma, pode-se também afirmar que as percepções de características sócio-profissionais negativas dos trabalhadores, apresentadas por ambas as etnias, são semelhantes, embora se possa constatar uma tendência para a etnia negra valorizar mais aspectos relacionados com o cumprimento de horários, nas negativas e positivas.

Os dados sobre as percepções de características sócio-profissionais positivas dos trabalhadores imigrantes negros dos PALOP africanos, achamse na Tabela 4

Tabela 4 - Percepções de características sócio-profissionais positivas dos trabalhadores imigrantes negros dos PALOP africanos em função da etnia

\begin{tabular}{|c|c|c|c|c|c|}
\hline \multirow{2}{*}{$\begin{array}{c}\text { Caracteristicas } \\
\text { Positivas }\end{array}$} & \multicolumn{2}{|c|}{ Etria Branca } & \multicolumn{2}{c|}{ Caracteristicas } & \multicolumn{2}{c|}{ Etria Negra } \\
\hline & $n$ & $\%$ & Positivas & $n$ & $\%$ \\
\hline Trabalhador & 22 & 22 & Honesto & 21 & 21 \\
\hline Responsável & 17 & 17 & Trabalhador & 18 & 18 \\
\hline Resistente & 13 & 13 & Profissional & 14 & 14 \\
\hline Alegre & 11 & 11 & Obediente & 12 & 12 \\
\hline Simpático & 10 & 10 & Ambicioso & 10 & 10 \\
\hline Esforçado & 9 & 9 & Resistente & 9 & 9 \\
\hline Disponivel & 8 & 8 & Empenhado & 7 & 7 \\
\hline $\begin{array}{c}\text { "Outras" (Submisso, } \\
\text { Força de Vontade, } \\
\text { Empenhado e } \\
\text { Profissional) }\end{array}$ & 10 & 10 & $\begin{array}{l}\text { "Outras" (Dedicado, } \\
\text { Sincero, Respeitador } \\
\text { e Pontual) }\end{array}$ & 9 & 9 \\
\hline Total & 100 & 100 & Total & 100 & 100 \\
\hline
\end{tabular}

Segundo esses dados, ser "trabalhador" e "responsável" ocupam o primeiro e segundo lugares para os brancos, enquanto que para os negros é ser "honesto" e "trabalhador". Portanto, ser "trabalhador" está presente em ambos os grupos de forma seme- lhante. Saliente-se que ser "responsável" e "honesto" já tinha sido apresentado por ambos os grupos para as características positivas dos trabalhadores em geral (Tabela 2).

A característica "resistente" é citada por ambas as etnias, embora surja em terceiro lugar para a branca e em sexto para a negra, demonstrando que este aspecto é percebido como importante para os imigrantes, talvez devido às duras e difíceis condições de trabalho que enfrentam, geralmente mais agravadas do que para os outros trabalhadores. A este propósito, pode-se dizer que muitos dos trabalhadores imigrantes dos PALOP desempenham tarefas laborais nos setores com piores condições de trabalho, mais baixas remunerações e menores possibilidades de promoção, mesmo quando possuem escolaridade acima da média.

Já as características positivas "alegre", "simpático", "esforçado" e "disponível” são citadas pelos brancos, com frequências semelhantes e referem-se a qualidades pessoais e de temperamento, mais do que profissionais, enquanto que os negros apresentam características profissionais, como "profissional" e "empenhado", e pessoais como "obediente" e "ambicioso". Importante assinalar que os brancos apontam o ser "submisso", colocado na categoria "outras", embora com baixa frequência, enquanto que a característica "obediente" surge citada em quarto lugar pelos negros. Este aspecto da personalidade dos imigrantes, a par da resistência e do empenho/esforço, qualificam a luta diária deles, pontuada por dificuldades econômicas e sociais, que exigem esforços redobrados na luta pelos direitos sociais e laborais. A obediência e a submissão têm pouca expressão como característica positiva só para a etnia branca, pois, para a negra, na tabela de profissões de baixo estatuto social, estas características são muito valorizadas no desempenho de tarefas rotineiras e repetitivas, em que não se exige planejamento autônomo e criatividade. Além disso, a "pontualidade/falta de pontualidade" foram citados anteriormente para os trabalhadores em geral pela etnia negra, o que complementa a caracterização destas profissões, marcando as vivências dos indivíduos e a sua ação nos mais variados contextos de existência, muito particularmente no sócio-laboral. 
Finalmente, a Tabela 5, traz as percepções de características sócio-profissionais negativas dos trabalhadores imigrantes negros dos PALOP africanos em função da etnia.

Tabela 5 - Percepções de características sócio-profissionais negativas dos trabalhadores imigrantes negros dos PALOP africanos em função da etnia

\begin{tabular}{|c|c|c|c|c|c|}
\hline \multirow{2}{*}{$\begin{array}{c}\text { Caracteristicas } \\
\text { Negativas }\end{array}$} & \multicolumn{2}{|c|}{ Etria Branca } & \multirow{2}{*}{$\begin{array}{c}\text { Caracteristicas } \\
\text { Negativas }\end{array}$} & \multicolumn{2}{|c|}{ Etnia Negra } \\
\hline & $n$ & $\%$ & & $n$ & $\%$ \\
\hline Irresponsável & 25 & 25 & Pouco Pontual & 26 & 26 \\
\hline Desqualificado & 19 & 19 & Desonesto & 16 & 16 \\
\hline Preguiçoso & 15 & 15 & Preguiçoso & 15 & 15 \\
\hline Submisso & 14 & 14 & Desqualificado & 13 & 13 \\
\hline Lento & 10 & 10 & Submisso & 11 & 11 \\
\hline Discriminado & 9 & 9 & Desmotivado & 10 & 10 \\
\hline $\begin{array}{c}\text { "Outras" (Explorado; } \\
\text { Pouco Profissional e } \\
\text { Acomodado) }\end{array}$ & 8 & 8 & $\begin{array}{l}\text { "Outras" (Conflituoso, } \\
\text { Desistente, } \\
\text { Irresponsável e } \\
\text { Indolente) }\end{array}$ & 9 & 9 \\
\hline Total & 100 & 100 & Total & 100 & 100 \\
\hline
\end{tabular}

Para a etnia branca a característica "irresponsável" surge em primeiro lugar, seguida da de "desqualificado", enquanto que para a negra em primeiro lugar está o "pouco pontual", seguida da de "desonesto". As características "desqualificado", "preguiçoso" e "submisso" são referidas por ambos os grupos entre as mais importantes, embora com pequenas variações na frequência. Ser "lento" e "discriminado" só aparece citado com alta frequência pela etnia branca, enquanto que ser "pouco pontual", "desonesto" e "desmotivado" vêm pela negra.

Ora, tal como dito nas análises anteriores, voltam a surgir aspectos relacionados com pontualidade e submissão, esta última agora de forma mais evidente, parecendo caracterizar as vivências sóciolaborais dos imigrantes negros dos PALOP, a par da característica "preguiçoso", que já tinha surgido para os trabalhadores em geral.

Em suma, as diferenças nas percepções de características sócio-laborais entre trabalhadores em geral e trabalhadores negros dos PALOP africanos aparecem na característica positiva "resistente", citada só pelos imigrantes, e também por eles valorizadas a obediência, submissão e pontualidade, que se ligam aos aspectos e condições particulares do desempenho das suas profissões, que são vivenciadas de forma mais profunda e acentuada pelos trabalhadores imigrantes negros do que pelos brancos, refletindo, provavelmente, a sua precária e frágil situação profissional e social.

\section{Considerações finais}

Neste trabalho feito o estudo comparativo sobre as percepções de características sócio-profissionais (positivas e negativas) dos trabalhadores em geral (de etnia branca) e dos trabalhadores negros africanos, imigrantes dos países de língua oficial portuguesa, segundo a visão dos dois grupos, compondo uma amostra de 200 participantes que residem e trabalham na Grande Lisboa, com escolaridade entre o ensino secundário e o ensino superior e desempenhando majoritariamente funções de executante, pode-se verificar que existem semelhanças e diferenças na maneira de ver as questões propostas. E, dado o objetivo de clarificar tais percepções sociais para promover o desen-volvimento de mecanismos de facilitação da inclusão sócio-econômica e cultural dos imigrantes na sociedade que os acolhe, nomeadamente dos imigrantes africanos oriundos dos PALOP, que partilham com os portugueses um passado histórico, político, cultural e sócio-econômico comum de vários séculos, pode-se concluir que urge transformar as condições sócio-laborais dos imigrantes, tornando mais céleres e transparentes as condições de legalização e de permanência em Portugal, responsabilizando os empregadores e os cidadãos em geral pela denúncia de situações de exploração e de ilegalidade: necessita-se, como afirma Checa (2002) "de 'uma educação intercultural' como proposta de integração, que projete uma mudança de atitudes e fomente a tolerância, tanto na maioria autótone como nas minorias imigradas. Há que evitar o etnocentrismo, que de alguma maneira todas as culturas sentiram ao longo da sua história.", pois "é preciso reeducar para a convivência tolerante, para o respeito mútuo, para a igualdade e a dignidade culturais. Integração social deverá ser sinônimo de convivência e de respeito e não de assimilação"(pp- 113-114). Nesta perspectiva, para finalizar, fica uma mensagem de esperança e reconciliação, veiculada através do mito de origem do português moçambicano: 
"Lhe conto uma história. Me contaram, é coisa antiga, dos tempos de Vasco da Gama. Dizem que havia, nesse tempo, um velho preto que andava pelas praias a apanhar destroços de navios. Recolhia restos de naufrágios e os enterrava. Acontece que uma dessas tábuas que ele espetou no chão ganhou raízes e reviveu em árvore. Pois, senhor inspetor, eu sou essa árvore. Venho de uma tábua de outro mundo mas o meu chão é este, minhas raizes renasceram aqui. São estes pretos que todos os dias me semeiam." (Leite, 1998, p.48).

Que os imigrantes negros dos PALOP africanos em Portugal possam um dia ter como seu um mito semelhante, renascendo aqui como cidadãos na plenitude dos seus direitos e, fundamentalmente, como pessoas felizes e realizadas.

\section{Referências}

Bastos, J. G. P., \& Bastos, S. P. (1999). Portugal multicultural. Lisboa: Edições Fim de Século.

Carita, C., \& Rosendo, V. N. (1993). Associativismo cabo-verdiano em Portugal: Estudo de caso da Associação Cabo-Verdiana em Lisboa. Sociologia: Problemas e Práticas, 13, 135-152.

Carlos, L. P., Esteves, M. C., Franco, V., Gomes, T. F., Guibentif, P. Pires, R. P., \& Saint-Maurice, A. (1991). Portugal. País de imigração. Lisboa: Instituto de Estudos para o Desenvolvimento.

Checa, F. (2002). Los inmigrados: La discriminación y exclusión diseñada. Antropológicas, 6, 87-119.

Dicionário de Sociologia (2002). Porto: Porto Editora.

Faria, L. (1998). Desenvolvimento diferencial das concepções pessoais de inteligência durante a adolescência. Lisboa: Fundação Calouste Gulbenkian \& Junta Nacional de Investigação Científica e Tecnológica.

Fernandes, A. T. (1995). Etnicização e racização no processo de exclusão social. Sociologia, v.1, n.5, 7-35.

Ferreira de Castro, J. A. (1977). Obras de Ferreira de Castro. Porto: Lello \& Irmão Editores.
Leite, A.M.(1998). Oralidades e escritas nas literaturas africanas. Lisboa: Edições Colibri.

Lello, E., \& Lello, J. (1988). Lello universal. Porto: Lello \& Irmãos Editores.

Lima Santos, N. (1998). Representações sociais da identidade nacional dos portugueses. Em S. Castillo \& V. P. Rosa (Orgs.), Pós-colonialismo e identidade. Porto: Edições Universidade Fernando Pessoa.

Machado, F. L. (1997). Contornos e especificidades da imigração em Portugal. Sociologia: Problemas e Práticas, 24, 9-44.

Machado, F. L. (1998). Da Guiné-Bissau a Portugal: Luso-guinienses e imigrantes. Sociologia: Problemas e Práticas, 26, 9-55.

Machado, F. L. (1999). Imigrantes e estrutura social. Sociologia: Problemas e Práticas, 29, 52-75.

Monteiro, M. B. (2002). A construção da exclusão social nas relações interétnicas: Orientações teóricas e de investigação na perspectiva do desenvolvimento. Psicologia, v.16, n.2, 271-292.

Moscovici, S. (1979). Psychologie des minorités actives. Paris: PUF.

Pires, S. (2002). A etnicização da imigração na imprensa portuguesa. Antropológicas, 6, 247-263.

Saint-Maurice, A. (1994). Reconstrução das identidades no processo de emigração: A população cabo-verdiana residente em Portugal. Tese de Doutorado no ISCTE. Lisboa: Edição da autora.

Silva, M. C. \& Silva, S. (2002). Práticas e representações sociais face aos ciganos. O caso de Oleiros, Vila Verde. Antropológicas, 6, 57-86.

Simões, C. (2002). Da privação sócio-econômica à falência dos conceitos de suporte social e desenvolvimento: Reflexões para uma práxis interventiva. Análise Psicológica, v.3, n.20, 291-295.

S.O.S. Racismo (1992). Guia anti-racista. Lisboa: Sodilivros.

Xavier de França, D. \& Monteiro, B. (2004). A expressão de formas indiretas de racismo na infância. Análise Psicológica, v.4, n.22, 705-720. 